\title{
ETIQUETA ECOLÓGICA EUROPEIA: INSTRUMENTO RELEVANTE DE LIVRE MERCADO E PROTEÇÃO AMBIENTAL
}

\author{
Fábio Ferreira Morong \\ Universidade do Oeste Paulista - UNOESTE, curo de Direito, Presidente Prudente, SP. E-mail: \\ fabiomorong@hotmail.com
}

\section{RESUMO}

Este trabalho objetiva realizar um estudo sobre a Etiqueta Ecológica Europeia como um importante mecanismo de livre mercado na União Europeia, materialmente representado por um selo de qualidade, que viabiliza a promoção de serviços e produtos industrializados que tenha um impacto ambiental reduzido. Leva em conta a suas características gerais e peculiares, enfatizando as questões relativas ao seu regime jurídico. O método utilizado foi o dedutivo legal, aplicando a interpretação dos textos legais, jurisprudenciais e doutrinários da União Europeia e Espanha. 0 estudo conclui que etiqueta ecológica europeia é um instrumento importante de livre mercado europeu, que propicia uma escolha ao cidadão europeu no sentido de expressar, através do ato livre de compra, a sua intenção de proteger o meio ambiente, estimulando os produtores a alterarem seu modo de produção, favorecendo assim o desenvolvimento sustentável entre o sistema comunitário de Estados-Membros,servindo de exemplo aos demais países do mundo.

Palavras-chave: Etiqueta Ecológica. Impacto Ambiental de Produtos e Serviços. Livre Mercado. Consumidor. Desenvolvimento Sustentável.

\section{LABEL ECOLOGICAL EUROPEAN: RELEVANT INSTRUMENT OF FREE MARKET AND ENVIRONMENTAL PROTECTION}

\begin{abstract}
This work aims to conduct a study on the European ecological label as an important free market mechanism in the European Union, materially represented by a seal of quality, which enables the promotion of services and manufactured products that have a reduced environmental impact. It takes into account their general and specific characteristics, emphasizing issues relating to legal system. The method used was the legal deductive applying the interpretation of legal texts, case law and doctrine of the European Union and Spain. The study concludes that European ecological label is an important tool of free European market, which provides a choice to the European citizen in order to express, through the purchase of free act, your intention to protect the environment by encouraging producers to change their way production, favoring sustainable development between the Community system of Member States, setting an example to the rest of the world.
\end{abstract}

Keywords: Ecological label. Environmental Impact of Products and Services. Free Market. Sustainable Consumer. Development. 


\section{INTRODUÇÃO}

A Etiqueta Ecológica Europeia ${ }^{1}$ representa um ponto de ligação entre a proteção ambiental e a política de consumo e mercado europeu, uma vez que possui dupla característica, a saber, auxilia o consumidor a orientar-se e escolher determinados produtos e serviços menos nocivos para o meio ambiente e, ao mesmo tempo propicia uma crescente incidência sobre a demanda de mercado para serviços e produtos com impacto ambiental reduzido durante todo o seu ciclo de vida.

Este instrumento, representado simbolicamente por um "selo" de qualidade ambiental e constituído a partir de critérios científicos para sua concessão, dotado de seu próprio sistema jurídico e sujeitos a certos controles e vigilâncias, constitui um mecanismo de mercado que permite que em determinadas áreas exista uma contribuição a ponto de reduzir os danos causados pelo consumo maciço de bens e serviço. Ao mesmo tempo, ajuda a desenvolver a investigação, em especial das tecnologias limpas, resultando daí uma inovação para a indústria e incentivos ao livre mercado europeu e também mundial.

Como consequência, Etiqueta Ecológica Europeia incorpora o meio ambiente na estratégia competitiva da empresa, permitindo que os produtos dessas características tenham maior demanda de mercado, estimulando uma nova maneira de utilizar uma economia de livre mercado que encoraja e incentiva a indústria a produzir seus produtos, e desenvolver serviços alternativos que favoreçam a proteção do meio ambiente, estimulando consequentemente o desenvolvimento sustentável.

O presente trabalho tem como objetivo realizar um estudo sobre a Etiqueta Ecológica Europeia apresentando aspectos jurídicos, ambientais e econômicos que a demonstra ser um importante mecanismo de livre mercado na União Europeia, capaz de propiciar uma escolha aos cidadãos europeus de expressarem, através do ato livre da compra, a sua intenção de proteger o meio ambiente, incentivando os produtores a mudarem seu modo de produção, favorecendo assim o desenvolvimento sustentável entre o sistema comunitário de Estados-Membros, servindo de exemplo aos demais países do mundo.

\section{METODOLOGIA}

Para cumprir o objetivo proposto, o presente trabalho seguirá os métodos dialéticodedutivo, com emprego de pesquisa à legislação, doutrina e jurisprudência acerca da matéria objeto do estudo.

\footnotetext{
${ }^{1}$ Este instrumento está fundamentado legalmente pelos de regulamentos (CE) no 880/92, Regulamento (CE) № 1980/2000 e (CEE) no 66/2010 da União Europeia. 


\section{CARACTERÍSTICAS GERAIS DA ETIQUETA ECOLÓGICA EUROPEIA}

A doutrina entende, segundo Manuela Mora Ruiz (2007), que a Etiqueta Ecológica Europeia é um instrumento de tutela ambiental em âmbito europeu, de caráter voluntário, que conecta a uma política ambiental com base no produto e serviço de livre mercado como um meio de proteção ambiental, de modo que busca potencializar o uso e fabricação de produtos considerados "limpos e verdes", através da sua procura no mercado aberto por uma rede de consumidores mais bem esclarecidos e orientados.

Por outro lado, pode-se considerar que as Etiquetas Ecológicas Europeias são instrumentos de estímulo econômico e de informação aos consumidores europeus que visam a proteção do meio ambiente.Consiste em geral, na concessão por um órgão neutro de um selo, logotipo ou etiqueta de aprovação de produtos e serviços que, diante de um processo voluntário de avaliação fundamentado em critérios definidos, indica um menor impacto ambiental em relação a produtos e serviços equivalentes (XAVIER; CARMELO J.,XOSÉ VÁZQUEZ, 2007).

Destarte, podemos concluir que Etiqueta Ecológica Europeia é de fato um instrumento de grande relevância no livre mercado na União Europeia, materialmente representada por um selo de qualidade, o que possibilita, através de informações técnicas fornecidas aos consumidores, à promoção de serviços e produtos comerciais e industriais que tenham um impacto reduzido no ambiente, estimulando assim o desenvolvimento sustentável.

\section{FINALIDADES DO INSTRUMENTO}

As principais finalidades deste instrumento são, em primeiro lugar, o incentivo aos fabricantes, os produtores e empresários para a implementação de atividades que melhorem a relação de produtos e atividades envolvidas com o meio ambiente, em particular, através da redução impactos ambientais além das disposições das regras pertinentes. Em segundo lugar, o estímulo aos consumidores e usuários, além do público em geral, para exercerem os seus "poderes" de mercado e, assim, tornarem-se incentivadores permanentes das atividades de melhoria na sua relação com o entorno de produtores e fabricantes (BETANCOR RODRÍGUEZ, 2001).

Ou seja, o propósito é caracterizado por um novo método de utilização da economia de mercado, a fim de incentivar a indústria a produzir produtos alternativos que favoreçam a conservação do meio ambiente, através de mais e melhor informação prestada aos consumidores sobre o impacto ambiental dos produtos que compram e utilizam e, acima de tudo, promovendo o 
crescimento da demanda por determinados produtos que possuam a etiqueta ecológica que garante a sua responsabilidade ambiental (PINO MERINO, 1993).

\section{UM SÍMBOLO EUROPEU}

O "selo" é uma comunidade simbolizada por uma "flor"2 caracterizado por uma letra "E" de Europa no centro, composto por doze estrelas que representam cada um dos Estados-Membros, e uma haste formada por um recurso com duas folhas, eles também sugerido por dois traços, um maior e um menor, em cada lado. Este emblema deve incluir em seu corpo as informações de forma clara e compreensível sobre os critérios ecológicos para cada categoria de produtos.

Este símbolo, segundo FERNÁNDEZ DE GATTA SÁNCHES (2012), representa uma técnica administrativa utilizada para proteção do meio ambiente através da atuação pública que intervém, entre outras formas, mediante a acreditação dos organismos competentes para emitirem o referido emblema, e até com um papel ativo como gestora e dirigente do programa. A mesma técnica também serve para mover o mercado quando a administração atua na promoção da etiqueta, de seu significado e de sua importância para a proteção ambiental entre os consumidores, uma vez que dependem, em última análise, da eficácia deste instrumento para alcançar os objetivos através do consumo.

\section{A ADESÃo VOLUNTÁRIA E SEU ÂMBITO DE APLICAÇÃO}

A adesão ao sistema Etiqueta Ecológica Europeia possui um caráter voluntário e está definida por um regulamento específico, de aplicação direta e imediata por tanto (MORONG, 2009), incluindo os critérios materiais e de concessão da mesma. Não é possível haver instituição de normativas substantivas próprias sobre a etiqueta pelos Estados-Membros. Assim, estes somente podem regular os aspectos organizacionais que eventualmente contribuam à obediência da norma europeia (AZQUETA OYARZUN, 2002).

O sistema da Etiqueta Ecológica Europeia é composto por todos Estados membros do Espaço Econômico Europeu, ou seja, os países integrantes da União Europeia, além da Noruega, a Islândia e o Liechtenstein. E em relação ao seu âmbito de aplicação, inclui todos os bens e serviços fornecidos para distribuição, consumo ou utilização no mercado da União, mediante pagamento ou de forma gratuita(COMISSÃO EUROPEIA, 2013).

Estes serviços ou produtos devem conter algumas características peculiares, tais como: constituir um volume significativo de vendas e de comércio no mercado; presumir, em escala

\footnotetext{
${ }^{2} A$ imagem da etiqueta se estabelece no Anexo II do Regulamento (CE) no 66/2010, do Parlamento Europeu e do Conselho, de 25 de Novembro de 2009, relativo a Etiqueta Ecológica da União Europeia (DOUE L 27, 30.1.2010). 
mundial ou regional, os efeitos ambientais significativos;apresentar um relevante potencial para otimizar o meio ambiente através de escolha do consumidor, além de estabelecer um estímulo para a investigação, por parte dos fabricantes ou prestadores de serviços, de vantagens competitivas por produtos que possam ansiar e merecer a Etiqueta Ecológica Europeia. São excluídos desses âmbitos os medicamentos para uso humano, drogas veterinárias e dispositivos sanitários (LOZANO CUTANDA, 2007).

\section{O SISTEMA DE CRITÉRIOS E REQUISITOS DE AVALIAÇÃO E CUMPRIMENTO DA ETIQUETA ECOLÓGICA EUROPEIA: CARACTERÍSTICAS GERAIS}

As Etiquetas Ecológicas Europeias são estabelecidas por categorias de produtos com base em vários critérios ao longo de todo o seu ciclo de vida. Estes critérios são definidos por organismos independentes designados pelos Estados-Membros, que não intervém no mercado e tem aplicação controlada por um processo de certificação de auditoria.

A tal efeito, para contribuir com a elaboração e revisão dos critérios da Etiqueta Ecológica, foi criado o Comitê da Etiqueta Ecológica da União Europeia, que está composto pelos organismos competentes que são responsáveis, no âmbito dos Estados Membro da União Europeia, à comprovação do acatamento dos requisitos estabelecidos em seu regulamento próprio e demais normas, com a finalidade de proceder à concessão da referida Etiqueta.

O Comitê é também composto por representantes de todos os interessados em certas categorias de produtos, ou seja, organizações empresariais, empresas, organizações de consumidores, fabricantes, sindicatos, etc. Portanto, este Comitê é responsável por desenvolver os critérios relativos a constituição da Etiqueta Ecológica bem como os requisitos de avaliação de comprovação de cumprimento dos mesmos (PINO MERINO, 1993).

Os critérios são determinados de maneira científica e se estabelecem levando em conta os impactos ambientais mais significativos, como por exemplo o consumo de energia e recursos, a poluição, resíduos, a possibilidade de redução de impacto ambiental por a sua durabilidade e a capacidade de reutilização, além da substituição de produtos perigosos por outros mais seguros, etc.

Estes critérios instituem os requisitos e condições ambientais que deverão cumprir o produto ou serviço para obter a concessão da Etiqueta Ecológica Europeia, e depois de sua aprovação, são válidos geralmente entre 03 a 05 anos, variando de acordo com a categoria específica de produto ou serviço (AZQUETA OYARZUN, 2002). 
Também devem ser determinados os métodos de avaliação do cumprimento dos critérios por parte dos produtos e serviços concretos e a comprovação das condições de utilização da etiqueta, assim como o prazo de validade dos referidos critérios e requisitos.

Expirado esse lapso temporal, proceder-se-á a revisão, eventualmente para tornarem-se mais restritivo em função da evolução do mercado e do progresso científico e tecnológico, com o objetivo de melhorar o desempenho ambiental da respectiva categoria de produto ou serviço que ostenta a Etiqueta, ademais de estimular o consumo no livre mercado (LOZANO CUTANDA,2007).

\section{INSTRUMENTO DE CONTROLE E MONITORAMENTO DE MERCADO}

Manuela Mora Ruiz (2007) destaca que em relação aos sistemas de Etiqueta Ecológica Europeia e o regime jurídico existentes nos Estados-Membros, observa-se um caráter de harmonização, coordenação e compatibilidade entre todos os emblemas de acordo com a postura de harmonização que prescreve a legislação comunitária. Ou seja, em caso de publicação de critérios para a utilização da Etiqueta Ecológica para uma categoria de produtos ou serviços, outros sistemas de Etiquetas Ecológicas nacionais ou regionais somente poderão ser incluídos se os critérios desses sistemas forem tão estritos como os da Etiqueta Ecológica Europeia, respeitando sempre a harmonização, a coordenação e compatibilidade de todos.

O controle e monitoramento da utilização Etiqueta Ecológica é realizado através dos órgãos competentes. Eles estão consentidos para verificar a qualquer momento o cumprimento dos critérios ecológicos do produto ou serviços e as condições de utilização da referido instrumento. 0 sistema de fiscalização do mercado e controle da utilização da Etiqueta Ecológica é regulado através das comprovações adequadas, de modo que qualquer publicidade falsa ou enganosa é proibida, assim como qualquer selo ou logotipo que induza confusão com Etiqueta Ecológica Europeia, prevendo-se atuações no caso de não cumprimento dos critérios da Etiqueta Ecológica (FERNÁNDEZ DE GATTA SÁNCHEZ, 2012).

As atuações mais destacáveis em caso de constatação de irregularidades resumem-se em: estabelecer a suspensão da utilização Etiqueta Ecológica quando se comprovam alterações que determinaram sua concessão, concedendo ao titular prazo para regularização da situação; e a anulação da concessão da Etiqueta, levando a extinção do contrato de utilização da mesma, se o titular não cumprir as condições e as exigências do prazo permitido. 
Além disso, a Administração também poderá instituir sistemas de intercâmbio de informações e experiências entre todos os órgãos e partes interessadas a fim de fortalecer a fiscalização do sistema de utilização do referido instrumento (BETANCOR RODRíGUEZ, 2001).

\section{CONSIDERAÇÕES FINAIS}

Verificou-se que Etiqueta Ecológica Europeia é um mecanismo de livre mercado que favorece o desenvolvimento sustentável, caracterizando-se pelo poder de demanda no mercado aberto por uma rede de consumidores europeus bem informados e orientados.

No campo específico, o estudo demonstrou que as características e objetivos mais relevantes da Etiqueta Ecológica Europeia traduzem-se na informação do consumidor para orientação e escolha de produtos menos nocivos ao meio ambiente; de igual forma o incentivo para os fabricantes, os produtores e empresários para realizarem atividades que visem melhorar a relação de produtos e atividades com o meio ambiente. Verifica-se que o crescimento da demanda por determinados produtos que ostentam a Etiqueta Ecológica assegura a sua responsabilidade ambiental através do exercício do poder de livre mercado por parte dos consumidores, que são elementos fundamentais que materializam o ponto comum de ligação entre proteção ambiental e política de consumo e mercado europeu.

O presente estudo também constatou que o regime jurídico do processo inerente à Etiqueta Ecológica Europeia demonstra um grau importante de harmonização, coordenação e compatibilidade enquanto à relação da política da União Europeia e os Estados-Membros que fazem parte do sistema de rotulagem ecológica, permitindo assim maior controle e fiscalização da utilização da Etiqueta Ecológica através dos órgãos competentes e até mesmo pelo Poder Judiciário.

O estudo conclui que Etiqueta Ecológica Europeia é um importante instrumento de livre mercado europeu, o que dá opção ao cidadão europeu de expressar, através do ato livre da compra, a sua intenção de proteger o meio ambiente, contribuindo à conscientização ambiental do consumidor, ademais de propiciar que os serviços e produtos dessas características tenham demanda no mercado, estimulando os produtores a mudar seu modo de produção, favorecendo o desenvolvimento sustentável entre o sistema comunitário de Estados-Membros,servindo de exemplo aos demais países do mundo. 


\section{REFERÊNCIAS}

AZQUETA OYARZUN, Diego. Introducción a la economía ambiental.Madrid: McGraw Hill, Interamericana de España, 2002.

BETANCOR RODRÍGUEZ, Andrés. Instituciones de Derecho Ambiental. Madrid: La Ley, 2001. COMISIÓN EUROPEA. Medio Ambiente, Ecolabel.eu.Disponívelem< http://ec.europa.eu/environment/ecolabel/>. Acesso em: 02 fev. 2015.

EL PORTAL DE LA UNIÓN EUROPEA. Europa, Síntesis de la legislación de la UE, Consumidores, Etiquetado $y$ embalaje de los productos. Disponible en $<$ http://europa.eu/legislation summaries/consumers/product labelling and packaging/121090 e s.htm>. Acesso em 02 de fevereiro de 2015.

FERNÁNDEZ DE GATTA SÁNCHEZ, Dionisio. Sistema jurídicoadministrativo de protección del medio ambiente. Salamanca: Ratio Legis, 2012.

LOZANO CUTANDA, Blanca. Derecho ambiental administrativo. 8. ed. Madrid: Dykinson, 2007. MINISTERIO DE AGRICULTURA, ALIMENTACIÓN Y MEDIO AMBIENTE DE ESPAÑA. Disponible en $<$ http://www.magrama.gob.es/es/calidad-y-evaluacion-ambiental/temas/etiqueta-ecologica-dela-union-europea/preguntas frecuentes eee.aspx>. Acceso en 01 feb. 2013.

MORA RUIZ, Manuela. La gestión ambiental compartida: función pública y mercado. Valladolid: Lex Nova, 2007.

MORENO MOLINA, A. M. La empresa y el Derecho de la Unión Europea en el medio ambiente. Autorización. Evaluación de impacto ecológico. Prevención de accidentes. Control integrado de la contaminación. Eco-auditoría. Ecoetiqueta, en PAREJO, KRÁMER y otros: Derecho medioambiental de la Unión Europea. Madrid: McGraw Hill, 1996.

MORONG, Fábio Ferreira. "La Unión Europea y el Medio Ambiente en los Siglos XX y XXI", Revista Intertemas, Presidente Prudente/SP, v. 14, nov. 2009, p. 40. Disponible en < http://intertemas.unitoledo.br/revista/index.php/INTERTEMAS/article/viewFile/2729/2506>. Acceso en 03 feb. 2013.

ORTEGA ÁlVAREZ, Luis et al. Lecciones del Derecho del Medio Ambiente. 4. ed; Valladolid: Lex Nova, 2005.

PINO MERINO, Ángel del. El anuncio verde: marketing y comunicación medioambientales. Bilbao: Ediciones Deusto, 1993.

XAVIER Labandeira, CARMELO J. León y MARÍA XOSÉ VÁZQUEZ. Economía Ambiental. Madrid: Pearson Educación, S.A., 2007. 